\title{
Intrahospital critical patient transport from the emergency department
}

Omer Salt ${ }^{1}$, Metin Akpınar ${ }^{2}$, Mustafa Burak Sayhan ${ }^{1}$, Fatma Betül Örs ${ }^{1}$, Polat Durukan, Necmi Baykan+, Cemil Kavalci ${ }^{5}$

1Department of Emergency Medicine, Trakya University, Edirne, Turkey ${ }^{2}$ Department of Emergency Medicine, Van Training and Research Hospital, Van, Turkey ${ }^{3}$ Department of Emergency Medicine, Erciyes University, Kayseri, Turkey ${ }^{4}$ Department of Emergency Medicine, Nevşehir State Hospital, Nevşehir, Turkey ${ }^{5}$ Department of Emergency Medicine, Başkent University, Ankara, Turkey

Submitted: 31 August 2018

Accepted: 29 September 2018

Arch Med Sci 2020; 16 (2): 337-344

DOI: https://doi.org/10.5114/aoms.2018.79598

Copyright @ 2018 Termedia \& Banach

\begin{abstract}
Introduction: Although intrahospital transportation of critical patients from the emergency department (ED) is inevitable, it could also result in life-threatening situations. These situations, referred to as unwanted or unexpected events, mainly happen during the transportation of patients for diagnostic imaging or invasive procedures and result in a wide spectrum from vital condition changes, mental condition changes to cardiopulmonary arrest and death. Emergency departments have a high risk of facing such situations because these units are the first admission door of critical patients. Material and methods: This cross-sectional study was conducted prospectively, after interviewing the doctors who work in the ED actively, and by filling out the forms which were already prepared by the participants. Statistical analysis was performed according to the data received, and results were compared to the literature.

Results: Three hundred and forty-seven doctors from 52 hospitals were included in the study. 59.4\% $(n=206)$ of them were working at EDs which had more than 500 patients admitted. $51.9 \%(n=180)$ of doctors stated that they performed 10 or more critical patients' transport every day from their ED. $86.7 \%(n=301)$ of the participants stated that usage of control checklists would decrease the rate of unwanted situations and stated that they wanted to use them.

Conclusions: Intrahospital transportation of critical patients from the emergency room is a subject that should require attention by emergency room doctors, and using educated personnel, proper equipment, standardized protocols and control checklists will decrease the frequency of unwanted situations effectively.
\end{abstract}

Key words: emergency department, critically ill, in-hospital.

\section{Introduction}

Although intrahospital transportation of critical patients from the ED is inevitable, it could also result in life-threatening situations. Critically ill patients also have increased in-hospital mortality rates. In spite of the precautions taken during in-patient transportation, all of the unforeseen events that cause deterioration in the clinical situation of the patient or trauma of the patient (such as falling off the patient trol-

\author{
Corresponding author: \\ Omer Salt MD, Assist. Prof. \\ Department of \\ Emergency Medicine \\ Medical Faculty \\ Trakya University \\ 22060 Edirne, Turkey \\ Phone: +90 5325890711 \\ E-mail: dromersalt@gmail. \\ com
}


ley) and all previously unpredictable events are defined as unwanted status. In the meantime, many unexpected events can be experienced such as head and extremity traumas due to falling from the patient trolley, inadequate or overdose of the drug infusion, inadequate respiratory support, increased/decreased heart rate, sudden increase or decrease in blood pressure, detachment of oxygen probe, dislocation or obstruction of the endotracheal tube in intubated patients, dislocation of the nasogastric tube, dislocation of the urinary catheter, and removal of the arterial or venous catheter. In order to reduce the incidence of these events, transport of the critical patient should be performed by a team trained in this field, suitable equipment and checklists should be used, and if the patient's clinical condition is not suitable, the transport should not be done until the patient is stabilized [1-4]. Emergency departments have a high risk of facing such situations because these units are the first admission door of critical patients. The factors that determine the risk of unwanted situations during transport of critically ill patients from the ED to other intrahospital departments consist of the following: patient related, transport personnel related, transport equipment related and transport environment related [5]. Patient related factors are: severity of current disease, patient's hemodynamic condition, number of transports in the hospital. Transport personnel related factors are: personnel's training status, number of personnel, and experience of personnel [6]. Despite the fact that many procedural security precautions are taken during the transport of these critical patients, there is not a standard protocol that is accepted and used globally. In one study, it was pointed out that the rate of unwanted situations during critical patient transport is $10-70 \%$ [7]. Such a high rate emphasizes the importance of this matter clearly. Many departments use the critical patient transport guidelines which were prepared by their own associations [8-11]. Despite all of these precautions, critical patients still face higher risk of mortality and morbidity during intrahospital transport [12-14]. Careful planning, usage of proper and educated personnel, and sufficient equipment can decrease this risk level $[9,15]$. It is also emphasized that frequent practice of doctors, nurses and personnel who have the task of intrahospital transport is quite important to decrease the rate of unwanted situations [4].

Emergency departments are fateful units because of the fact of being critical patients' primary application unit. These patients are transported to other units of the hospital in order to undergo radiological imaging and invasive procedures and many unwanted situations can be encountered during these transports. Another factor that is responsible for increasing the risk of unwanted situation is the crowdedness of EDs. By the year of 2017, 137 million patients were admitted to the EDs in the United States, which has a population of 326 million people. On the other hand, this number exceeded 100 million in Turkey, which has a population of 81 million. The number of admissions to the ED being so high results in some difficulties. Despite many studies about intrahospital transport of critical patients in the literature, there are very few about intrahospital critical patient transport from the ED.

In this study, determination of rights and wrongs related to intrahospital critical patient transportation from emergency rooms was intended. It is thought that the study results can be compared to other studies in the literature and they will provide guidance for other studies in the future.

\section{Material and methods}

This prospective cross-sectional study was performed in a total of 52 hospitals (government hospitals, private hospitals, training and research hospitals and university hospitals) which are located in four cities in the Marmara Region which is located in the northwest of Turkey and holds about one fourth of inhabitants of the country. The study was started after getting permission from the local ethics committee. A total of 347 doctors accepted to participate to the study. During the hospital visits, emergency physicians, emergency residents, or chiefs who were on duty at the time were interviewed and the ones who agreed to participate in the study were read the informed consent form and signed. Then the participants were given the form which included 26 questions about participants' demographic data, the protocols of critical patient transport in their hospital and the "Intrahospital Critical Patient Transport Quick Checklist" (Appendix 1). The checklist that was presented to the physicians in this study is the most widely accepted and used checklist among the checklists for clinicians. There are also other checklists that are commonly used (Appendix 2, 3).

The participants were asked if they want to use the "Critical Patient Transport Quick Checklist" in their daily practice in the last question of the form. Statistical evaluation was performed by using 10240642 serial code IBM SPSS Statistics for Windows, Version 19.0. (Armonk, NY. USA, IBM Corp.) The frequencies and percentages were given as descriptive statistics. The $\chi^{2}$ test was used to evaluate the relationship between qualitative variables. While assessing the relationship between qualitative variables when the result ended up below 5\%, Fisher's exact test was used. 


\section{Results}

The study was performed with 347 doctors who work actively in ED. Out of visited hospitals, 10 (19.2\%) were university hospitals, 8 (15.4\%) were private hospitals, 15 (28.8\%) were training and research hospitals and 19 (26.6\%) were government hospitals. Out of doctors who participated in the study, 96 (27.7\%) worked in university hospitals, $169(48.7 \%)$ in training and research hospitals, $16(4.6 \%)$ in private hospitals and 66 (19\%) in government hospitals. The demographic characteristics of participants' hospitals are shown in Table I. Most of the participants $(60.3 \%, n=209)$ were working in hospitals that had daily admission to the ED of more than 500 patients.

$22.5 \%(n=78)$ of participants stated that more than 1000 patients applied to their ED, and $37.8 \%$ $(n=131)$ of them remarked this number between 500 and 1000 . When the participants were asked about the total percentage of critical patients admitted to the ED, $20.7 \%(n=72)$ stated the rate as $10-15 \%, 32.6 \%(n=113)$ of them stated this rate as $5-10 \%$. When they were asked if profit and loss account was performed before transport, $90.5 \%$ ( $n=314)$ of the participants answered "yes". Most of the participants ( $n=278,79.5 \%)$ stated that 1-20 critical patient transports were performed daily in the ED. All of the participants replied "no" to the question which asked "if there was a written procedure or control checklist during the transports". But 163 (47.0\%) participants stated that they always followed non-written and customary procedures. Only 69 (19.9\%) remarked that they had a special patient transport team. Only half of the participants ( $n=179,51.6 \%)$ stated that the personnel in the team had received advanced life cardiac support education. It was determined that only $21.6 \%$ of the personnel in these teams had received critical patient transport education periodically. The frequency of adverse events in hospitals where critical patient transport was carried out by trained teams was $2 \%$. This rate was up to $9 \%$ in the transfer by uneducated teams. When both conditions were compared, a statistically significant difference was found in the hospitals where there were trained teams ( $p=0.018)$. Two hundred and nine $(60.2 \%)$ participants stated that they encountered an unwanted situation during critical patient transport from the ED before. One hundred and eighty-eight (54.2\%) participants stated that they encountered an unwanted situation in 1 out of 20 transports. The general incidence of unwanted events was only $5 \%$ in our study. While this rate was below $1 \%$ in hospitals using checklist for critically ill transport, this rate was found to be up to $12.2 \%$ in clinics that did not use any standardized protocol and this difference was statistically significant $(p=0.024)$. When the participants were asked about the most common adverse events they encountered, saturation changes were obtained with a maximum rate of $23 \%(n=80)$. This was statistically significantly higher than other adverse events $(p=0.02)$. One hundred and thirty-nine $(40.1 \%)$ participants stated that they used transport ventilators during intubated patient transports. Only $82(23.6 \%)$ used an infusion pump in order to maintain fluid resuscitation during patient transports. When the groups that used a bag valve mask (40.1\%, $n=139$ ) during the transport and used a transport ventilator $(59.9 \%, n=208)$ were compared with each other in terms of unwanted event development rate, no statistically significant difference was found between them $(p=0.08)$. However, when the group using the infusion pump during transport $(23.6 \%, n=82)$ and the group that did not use one were compared to each other in terms of unwanted event development rate, the rate of unwanted events in the group using the infusion pump was $2.4 \%$, while this rate was found to be $8.7 \%$ in the group that did not use one and this was statistically significant $(p=0.028)$. The list and frequency of unwanted events that participants faced in the ED are shown in Table II.

When they were offered to assess if the "Intrahospital Critical Patient Transport Quick Checklist" would be useful for patient and staff security, most of them $(n=316,91.1 \%)$ replied "Yes". $86.7 \%$

Table I. Demographic characteristics of participants and hospitals

\begin{tabular}{|c|c|}
\hline Official duty in the Emergency Department & $N(\%)$ \\
\hline Chief & $32(9.2)$ \\
\hline Emergency physician & $69(19.9)$ \\
\hline Emergency resident & $181(52.2)$ \\
\hline Junior doctor & $65(18.7)$ \\
\hline \multicolumn{2}{|l|}{ Daily patient admission to ED: } \\
\hline $100-200$ & $63(18.2)$ \\
\hline $200-500$ & $75(21.6)$ \\
\hline $500-1000$ & $131(37.8)$ \\
\hline More than 1000 & $78(22.5)$ \\
\hline \multicolumn{2}{|l|}{ Rate of critical patients: } \\
\hline $1-5 \%$ & $59(17)$ \\
\hline $5-10 \%$ & $153(44.1)$ \\
\hline $10-15 \%$ & $113(32.6)$ \\
\hline More than $15 \%$ & $22(6.3)$ \\
\hline \multicolumn{2}{|l|}{$\begin{array}{l}\text { How many critical patient transports do } \\
\text { you perform in your ED daily? }\end{array}$} \\
\hline $1-10$ & $167(48.1)$ \\
\hline $10-20$ & $109(31.4)$ \\
\hline $20-30$ & $54(15.6)$ \\
\hline More than 30 & $17(4.9)$ \\
\hline
\end{tabular}


Table II. Unwanted events during critical patient transport

\begin{tabular}{|lc|}
\hline Unwanted event & $N(\%)$ \\
\hline \begin{tabular}{l} 
Patient related: \\
\hline Saturation change (increase/decrease)
\end{tabular} & $80(23.1)$ \\
\hline $\begin{array}{l}\text { Arterial blood pressure change } \\
\text { (increase/decrease) }\end{array}$ & $42(12.1)$ \\
\hline $\begin{array}{l}\text { Convulsion } \\
\text { Change in respiratory rate }\end{array}$ & $9(2.6)$ \\
\hline $\begin{array}{l}\text { (increase/decrease) } \\
\text { Cardiopulmonary arrest }\end{array}$ & $35(10.1)$ \\
\hline \begin{tabular}{l} 
Transport equipment related: \\
\hline Detachment of oxygen probe
\end{tabular} & $54(15.6)$ \\
\hline \begin{tabular}{l} 
Infusion pump related \\
\hline Detachment of endotracheal tube
\end{tabular} & $15(4.3)$ \\
\hline \begin{tabular}{l} 
Dislocation of urinary catheter \\
\hline Dislocation of vascular access
\end{tabular} & $24(6.9)$ \\
\hline $\begin{array}{l}\text { Transport team related: } \\
\text { Improper placement of the patient on }\end{array}$ & $20(5.7)$ \\
\hline $\begin{array}{l}\text { Total of the patient from the patient trolley } \\
\text { the }\end{array}$ & $84.8)$ \\
\hline
\end{tabular}

( $n=301)$ of them stated that they wanted to use the checklist in their hospitals for daily practice.

\section{Discussion}

Critical patient transport is a fateful procedure, because it has high potential risks. Many parameters effect this matter in terms of patient and staff security. The point that should be considered primarily is whether the transport is necessary or not. Before every transportation, a loss and profit account must be performed and the decision must be made after it. In a study [16] which included 180 critical patients, it was found that only $3.4 \%$ of transports were actually necessary. The rest of the transport decisions were made without making enough evaluation. In our study, a very high percentage of participants (90.5\%) stated that they made a loss and profit account before transportation. It is arguable whether this evaluation would be trustable since there is not a standard protocol which they can use.

In the studies performed earlier [17, 18], it is shown that the percentage of unwanted situations varies from $6 \%$ to $71.1 \%$. In our study this rate was found to be $5 \%$, which was very low. We think that the reason for this rate being so low is the result of participants assessing only major situations (cardiopulmonary arrest etc.) as unwanted situations. But it should not be forgotten that during the transport, even the acceleration-deceleration due to stretcher movement is an unwant- ed situation for a patient with intracranial hemorrhage.

In another study [19] the frequency of unwanted situations during intrahospital critical patient transport performed by special organized team was found to be $15 \%$, and when this was performed by untrained personnel it increased to more than $75 \%$. In our study, $51.6 \%(n=179)$ of participants stated that they had a special trained team for this procedure, but only $29.4 \%$ remarked that these team members attended periodical training. In contrast, $60.2 \%$ of participants said that they had encountered unwanted situations during patient transports. We think that the percentage being this is high is a result of the inefficient training and not having a standard procedure. When it is considered that the unwanted situation percentage is decreased dramatically when the transport is performed by specially trained personnel, the importance of this team presence and the importance of periodical training-education will be understood better.

When the equipment used during the transports was evaluated, $40.1 \%(n=139)$ of participants stated that they used a bag valve mask for intubated patient transport, and $23.6 \%(n=82)$ stated that they used an infusion stand during fluid resuscitation. Particularly critical patients in need of intensive care are also in need of vasopressor support, and the use of an infusion pump is important to achieve this support. We think that such low rates increase the equipment related problems associated with unwanted situations.

When the hospitals were compared in terms of the rate of unwanted situations, this rate was found to be highest in government hospitals with $72.7 \%$, and this situation was statistically significant $(p<0.05)$. We think that the reason for such a high rate is related to excessive patient admission to government hospitals' EDs. Another important point in intrahospital critical patient transport from the ED is patients' cardiac monitoring. In a study [20], it was found that monitoring makes the patient follow-up safer and decreases the rate of unwanted situations significantly. Also in our study, it was found that a very high percentage of $99.4 \%$ of patients were followed up with defibrillator during transport. Monitoring the critical patients with a defibrillator has vital importance due to opportunities for a quick reaction to dysrhythmias (ventricular fibrillation etc.) that could happen.

When the hospitals were evaluated in terms of having a standard procedure on critical patient transport, the highest rate with 60\% was found in university hospitals and it was found to be statistically significant $(p<0.05)$. We think that this is due to fact that universities are more sensitive in this regard and also it could be related to low- 
er patient admission rates. But when the hospitals were compared in terms of having a special trained personnel transport team, the result was statistically insignificant $(p>0.05)$. We think that it could be related to insufficiency of giving importance to this matter and the insufficient number of transport personnel.

There are some limitations in our study. First of all, most of the unwanted events are not recorded due to official and judicial concerns. Therefore, it is not possible to obtain clear information about the types of events and their real numbers. Therefore, these data could not be included in our study. The information on unwanted events is based solely on the clinicians' declaration of the study form. There may be changes in terms of rates in real life.

There are many checklists and guidelines prepared to prevent all these mentioned unwanted situations [9, 21-25]. In a study [11], it was pointed out that usage of these checklists and guidelines decrease the rate of unwanted situations. In our study, it was determined that despite not already having a standardized checklist or guideline for all of the EDs, still a high percentage of emergency room doctors have positive opinions about such an attempt.

In conclusion, critical patient transport from the ED to other units of the hospital has vital importance due to including high risks. The transport should be performed by trained and experienced personnel in order to decrease these risks and proper equipment should be used during this process. If every ED used a standardized protocol and checklist it would help to decrease the rate of unwanted situations.

\section{Conflict of interest}

The authors declare no conflict of interest.

\section{References}

1. Budzyński J, Tojek K, Wustrau B, et al. The "cholesterol paradox" among inpatients - retrospective analysis of medical documentation. Arch Med Sci Atheroscler Dis 2018; 3: e46-57.

2. Jones HM, Zychowicz ME, Champagne M. Intrahospital transport of the critically ill adult. Dimens Crit Care Nurs 2016; 35: 133-46.

3. Fromm RE Jr, Dellinger RP. Transport of critically ill patients. J Intensive Care Med 1992; 7: 223-33.

4. Ong MS, Coiera E. Safety through redundancy: a case study of in-hospital patient transfers. Qual Saf Health Care 2010; 19: e32.

5. Bercault N, Wolf M, Runge I, et al. Intrahospital transport of critically ill ventilated patients: a risk factor for ventilator-associated pneumoniaVa matched cohort study. Crit Care Med 2005; 33: 2471-78.

6. Zuchelo LT, Chiavone PA. Intrahospital transport of patients on invasive ventilation: cardiorespiratory repercussions and adverse events. J Bras Pneumol 2009; 35 : 367-74.
7. Beckmann U, Gillies DM, Berenholtz SM, et al. Incidents relating to the intra-hospital transfer of critically ill patients: an analysis of the reports submitted to the Australian Incident Monitoring Study in Intensive Care. Intensive Care Med 2004; 30: 1579-85.

8. Day D. Keeping patients safe during intrahospital transport. Crit Care Nurse 2010; 30: 18-32.

9. Schwebel C, Clec'h C, Magne S, et al. Safety of intrahospital transport in ventilated critically ill patients: a multicenter cohort study. Crit Care Med 2013; 41: 1919-28.

10. Fanara B, Manzon C, Barbot O, et al. Recommendations for the intra-hospital transport of critically ill patients. Crit Care 2010; 14: R87.

11. Warren J, Fromm RE Jr, Orr RA, et al.; American College of Critical Care Medicine: guidelines for the inter- and intrahospital transport of critically ill patients. Crit Care Med 2004; 32: 256-62.

12. Gillman L, Leslie G, Williams T, et al. Adverse events experienced while transferring the critically ill patient from the emergency department to the intensive care unit. Emerg Med J 2006; 23: 858-61.

13. Warren J, Fromm RE, Orr RA, et al. Guidelines for the inter- and intrahospital transport of critically ill patients. Crit Care Med 2004; 32: 256-62.

14. Blumen IJ, Abernethy MK, Dunne MJ. Flight physiology. Clinical considerations. Crit Care Clin 1992; 8: 597-18.

15. Blakeman TC, Branson RD. Inter- and intra-hospital transport of the critically ill. Respir Care 2013; 58: 1008-21.

16. O'Leary RA, Marsh B, O'Connor P. Transfer of critically ill adults assessing the need for training. Ir J Med Sci 2018; 187: 585-91.

17. Waydhas C. Equipment review: intrahospital transport of critically ill patients. Crit Care 1999; 3: R83-9.

18. Wallen E, Venkataraman ST, Grosso MJ, et al. Intrahospital transport of critically ill pediatric patients. Crit Care Med 1995; 23: 1588-95.

19. Szem JW, Hydo LJ, Fischer E, et al. High-risk intrahospital transport of critically ill patients: safety and outcome of the necessary 'road trip'. Crit Care Med 1995; 23: 1660-6.

20. Almeida ACG, Neves ALD, de Souza CLB. Intra-hospital transport of critically ill adult patients: complications related to staff, equipment and physiological factors. Acta Paul Enferm 2012; 25: 471-6.

21. Ozcan N, Ozcan A, Kaymak C, Basar H, Kotanoglu M, Kose B. Comparison of prognostic value of $\mathrm{N}$-terminal pro-brain natriuretic peptide in septic and non-septic intensive care patients. Arch Med Sci 2017; 13: 418-25.

22. Daniel JW, Pinosky ML. A simple suction device to aid in transportation of the critically ill pediatric patient. Anesthesiology 1996; 85: 220-1.

23. Nuckols TK. Reducing the risks of intrahospital transport among critically ill patients. Crit Care Med 2013; 41: 2044-45.

24. Brunsveld-Reinders AH, Arbous MS, Kuiper SG, de Jonge E. A comprehensive method to develop a checklist to increase safety of intra-hospital transport of critically ill patients. Cri Care 2015; 19: 214.

25. Comeau OY, Armendariz-Batiste J, Woodby SA. Safety first! Using a checklist for intrafacility transport of adult intensive care patients. Crit Care Nurse 2015; 35: 16-25. 
Appendix 1. Critical patient transport quick checklist

Systematic control points before each patient transport:

\section{EQUIPMENT/HOSPITAL PREPARATION:}

- Patient label

- Preparing the appropriate equipment for the procedure

- Effective medication, $\mathrm{O}_{2}$ and battery reserve

- Circulation

- Isolated and safe venous access (fast injection,)

- Medication (emergency, sedation, analgesia, paralytic agents)

- Alarm settings and activation (ECG, intra-arterial pressure)

- Breathing :

- Ensuring the safety of the tube and confirming the position with direct graphy

- Adjustment of mechanical ventilation according to the patient

- Intubation equipment, bag valve mask, portable aspirator etc.

\section{TRANSPORT TEAM}

- At least 3 accompanying persons (including a physician with knowledge of the medical history of the patient)

\section{TRANSPORT ORGANIZATION}

- Confirmation of the time of the process will be performed

- Transport route open, elevators and emergency room accessible

- Operation equipment $\left(\mathrm{O}_{2}\right.$ and electrical equipment, ventilator, aspirator) required for continuation of treatment throughout the procedure

\section{CLINICAL STABILIZATION OF THE PATIENT}

- Appropriate preparation for each patient's clinical condition:

- Circulation: hemodynamic optimization (blood volume, vasopressors), hemostasis

- Respiration (orotracheal intubation, chest drainage, synchronization with mechanical ventilator)

- Neurological status: pupillary, GCS, intracranial pressure

- Sedation - analgesia - neuromuscular blockade - hypothermia

- The fractures are stabilized, burns and scars are covered

- Head lifted (if possible) (to prevent intracranial pressure increase) 
Appendix 2. Leiden University Medical Center Checklist [25]

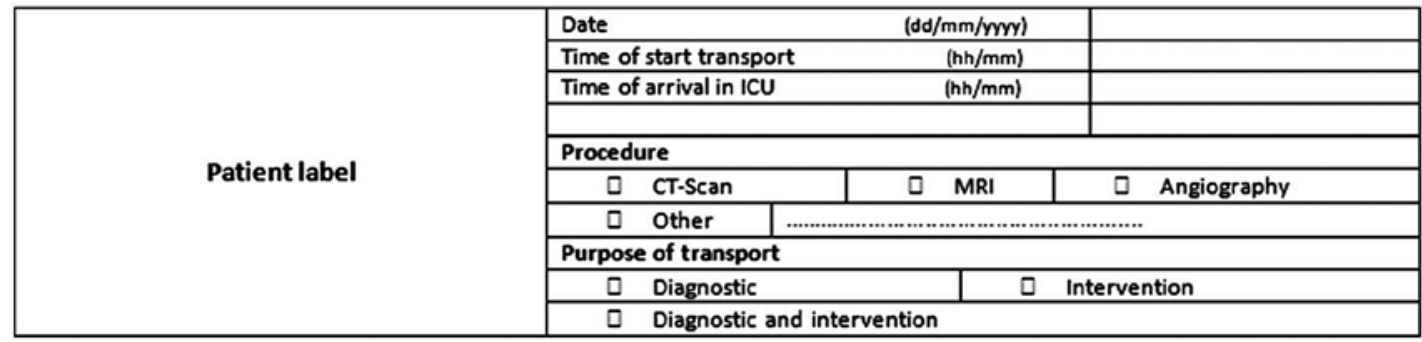

Pre-transport

\begin{tabular}{|l|l|l|l|}
\hline Equipment/materials & YES & NO & NA \\
\hline Transport bag present & & & \\
\hline Transport trolley fully charged & & & \\
\hline Defibrillator present & & & \\
\hline Manual resuscitation bag present & & & \\
\hline Sufficient oxygen level & & & \\
\hline Check length of i.v. tubes & & & \\
\hline In case of MRl; extend length i.v. tubes & & & \\
\hline Shut off necessary i.v. tubes & & & \\
\hline \hline
\end{tabular}

\begin{tabular}{|l|l|l|l|}
\hline Medication & YES & NO & NA \\
\hline Sufficient intravenous medication & & & \\
\hline Additional intravenous sedatives & & & \\
\hline Additional intravenous inotropics & & & \\
\hline Additional medication & & & \\
\hline Additional infusion pump & & & \\
\hline Additional intravenous fluids & & & \\
\hline Stop enteral nutrition & & & \\
\hline Stop enteral insulin & & & \\
\hline \hline
\end{tabular}

\begin{tabular}{|l|l|l|l|}
\hline In case of CT-Scan with contrast & YES & NO & NA \\
\hline Intravenous cannula 18GA present & & & \\
\hline Oral contrast administered & & & \\
\hline If "YES": & & & \\
\hline Renal protection according to protocol & & & \\
\hline
\end{tabular}

\begin{tabular}{|l|l|l|l|}
\hline Monitor & YES & NO & NA \\
\hline $\mathrm{EtCO}_{2}$ monitoring present & & & \\
\hline Check and set visual and audible alarm & & & \\
\hline
\end{tabular}

\begin{tabular}{|l|l|l|l|}
\hline Transport ventilator & YES & NO & NA \\
\hline Turn on the oxygen & & & \\
\hline Put HME filter between ventilator and ET/TT & & & \\
\hline Check and set visual and audible alarms & & & \\
\hline
\end{tabular}
\begin{tabular}{|l|l}
\hline ET/ $\pi$ depth $(\mathrm{cm})$ & \\
\hline
\end{tabular}

\begin{tabular}{|l|l|l|l|}
\hline Administrative & YES & NO & NA \\
\hline Register baseline vital signs overleaf & & & \\
\hline Switch patient in PDMS to "Transport" & & & \\
\hline Radiology department informed & & & \\
\hline Fill in MRI safety questionnaire & & & \\
\hline
\end{tabular}


Appendix 3. University of Texas Medical Branch adult critical care transport checklist

\begin{tabular}{|c|c|c|}
\hline Nursing - Prior to transport & $\begin{array}{c}\mathrm{RN} \\
\text { Initials }\end{array}$ & $\begin{array}{c}\text { RT } \\
\text { Initials }\end{array}$ \\
\hline \multicolumn{3}{|l|}{ RN given 45 minute notification from procedural area to prepare } \\
\hline \multicolumn{3}{|l|}{$\begin{array}{l}\text { Oral contrast given or } 20 \mathrm{~g} \mathrm{IV} \text { in antecubital (AC) vein obtained (for CT PE protocol) (If no AC IV can be } \\
\text { obtained, consider alternative of VQ scan) }\end{array}$} \\
\hline \multicolumn{3}{|l|}{ Upon notification of procedure, verify with MD that test is needed and consent obtained. } \\
\hline \multicolumn{3}{|l|}{ IF NOT Vented: Full oxygen tank obtained. RN will bring ambu bag with mask. } \\
\hline \multicolumn{3}{|l|}{ Transportation present } \\
\hline \multicolumn{3}{|l|}{ All invasive lines assessed and secured. All IV fluids and drips assessed for adequate amount. } \\
\hline \multicolumn{3}{|l|}{$\begin{array}{l}\text { If going to MRI: MRI checklist is completed. Retrieve MRI pump (from MRI; max } 3 \text { pumps available). } \\
\text { Obtain MRI pump tubing for needed infusions and add to Baxter tubing. Prepare infusions on MRI pump. }\end{array}$} \\
\hline \multicolumn{3}{|l|}{ Portable monitor obtained for continued level of care monitoring. Alarms set as appropriate for patient. } \\
\hline \multicolumn{3}{|l|}{ All equipment checked for function and battery length } \\
\hline \multicolumn{3}{|l|}{$\begin{array}{l}\text { If chest tube present, can patient tolerate chest tube to } \mathrm{H}_{2} \mathrm{O} \text { seal during transport or at target site? } \\
\text { Test patient on } \mathrm{H}_{2} \mathrm{O} \text { seal before transport as instructed below: } \\
\text { Suction available at target site: patient must tolerate } \mathrm{H}_{2} \mathrm{O} \text { seal twice the anticipated transport time. } \\
\text { No suction available at target site: patient must tolerate } \mathrm{H}_{2} \mathrm{O} \text { seal twice the anticipated total time off suction. } \\
\text { If air leak present and on mechanical ventilation: use portable suction during transport and at target site. }\end{array}$} \\
\hline \multicolumn{3}{|l|}{$\begin{array}{l}\text { If the patient is in PACU and PACU nurse is transporting patient, Anesthesia faculty aware that nurse will } \\
\text { be off the unit (Faculty: }\end{array}$} \\
\hline Respiratory Therapy - Vented Patients - Prior to transport & $\begin{array}{c}\mathrm{RN} \\
\text { Initials }\end{array}$ & $\begin{array}{c}\text { RT } \\
\text { Initials }\end{array}$ \\
\hline \multicolumn{3}{|l|}{$\begin{array}{l}\text { Obtain ambu bag with face mask and PEEP valve. Oxygen tank is FULL. One disposable } \mathrm{ETCO}_{2} \text { check } \\
\text { device available. }\end{array}$} \\
\hline \multicolumn{3}{|l|}{$\begin{array}{l}\text { Transport ventilator set up and trialed to assess patient tolerance and stability. If } P E E P \leq 8 \text { and } \mathrm{FiO}_{2} \leq 50 \% \text {, } \\
M D \text { approval and order may be obtained for transport via manual bag/valve ventilation in situations in } \\
\text { which a delay may be incurred and a risk: benefit ratio has been evaluated. Portable continuous } \mathrm{ETCO}_{2} \\
\text { monitor in place. }\end{array}$} \\
\hline Nursing/Respiratory Therapy - At procedural site & $\begin{array}{c}\mathrm{RN} \\
\text { Initials }\end{array}$ & $\begin{array}{c}\text { RT } \\
\text { Initials }\end{array}$ \\
\hline \multicolumn{3}{|l|}{ Switch to procedural area monitor if available. Transport monitor plugged in and charging. } \\
\hline \multicolumn{3}{|l|}{$\begin{array}{l}\text { Report given to procedural area RN (if ICU RN is not staying, and patient is going to an area other than } \\
\text { Cardiac Cath Lab or GI suite, physician order is required) }\end{array}$} \\
\hline \multicolumn{3}{|l|}{ RN confirms vital signs are stable prior to leaving patient } \\
\hline \multicolumn{3}{|l|}{ RT places patient on procedural area ventilator } \\
\hline \multicolumn{3}{|l|}{ RT and RN agree that patient's respiratory status is stable and RT may leave } \\
\hline RT will stay with patient if patient remains on transport ventilator & & \\
\hline
\end{tabular}

